\title{
Erratum
}

\section{Migrations or local interactions? Spheres of interaction in third-millennium BC Central Europe-ERRATUM} Jan Koláŕ

Published by Cambridge University Press, 1 September 2020

Due to a production error, Figure 4 in this article was incorrectly replaced with a new version of Figure 1. The correct versions of both figures are reproduced below.

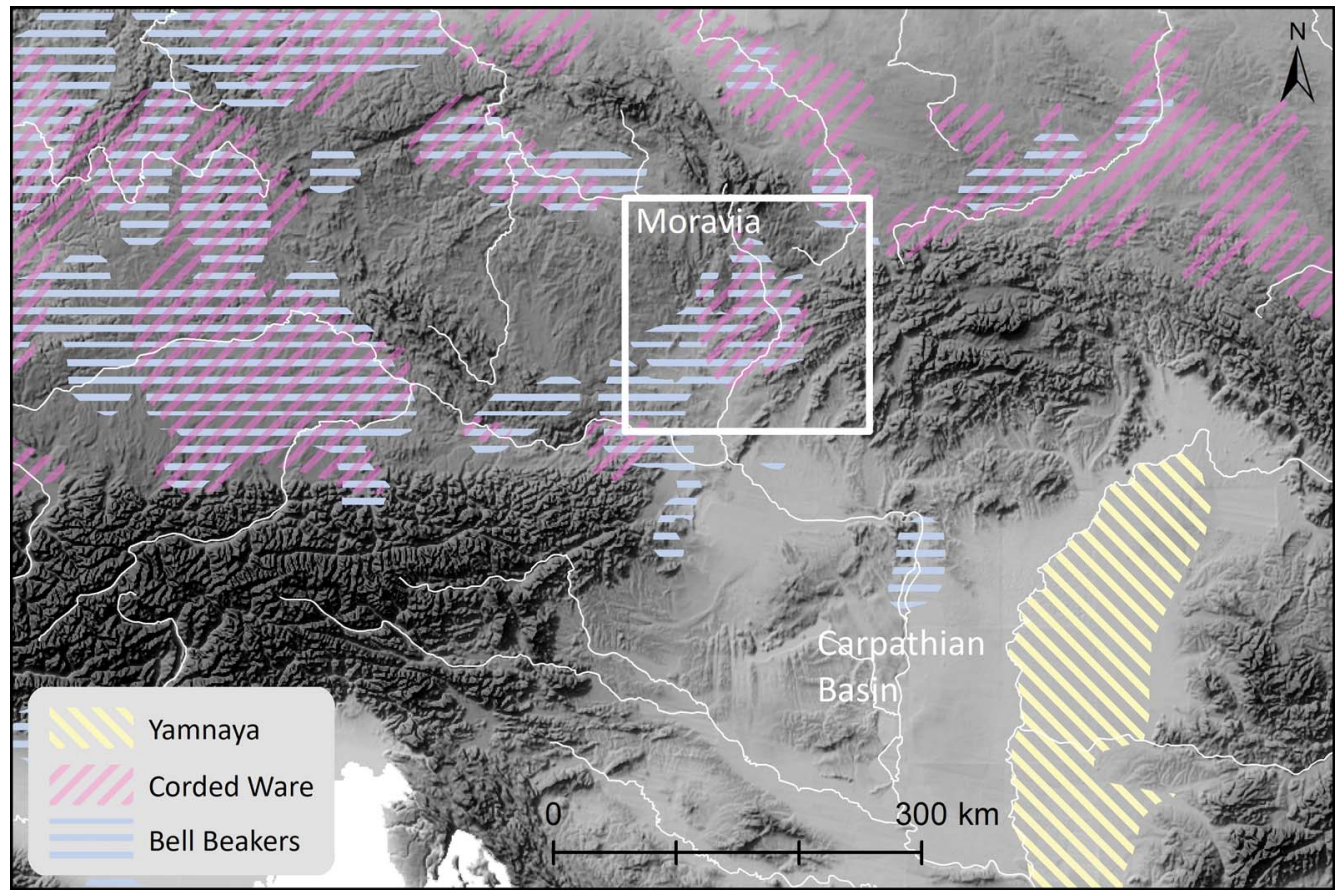

Figure 1. Map of Central Europe showing the main archaeological groups of the third millennium BC (figure by J. Kolâr, based on Gerling et al. 2012; Bilger 2018; Kolãr 2018).

(C) The Author(s), 2020. Published by Cambridge University Press on behalf of Antiquity Publications Ltd 


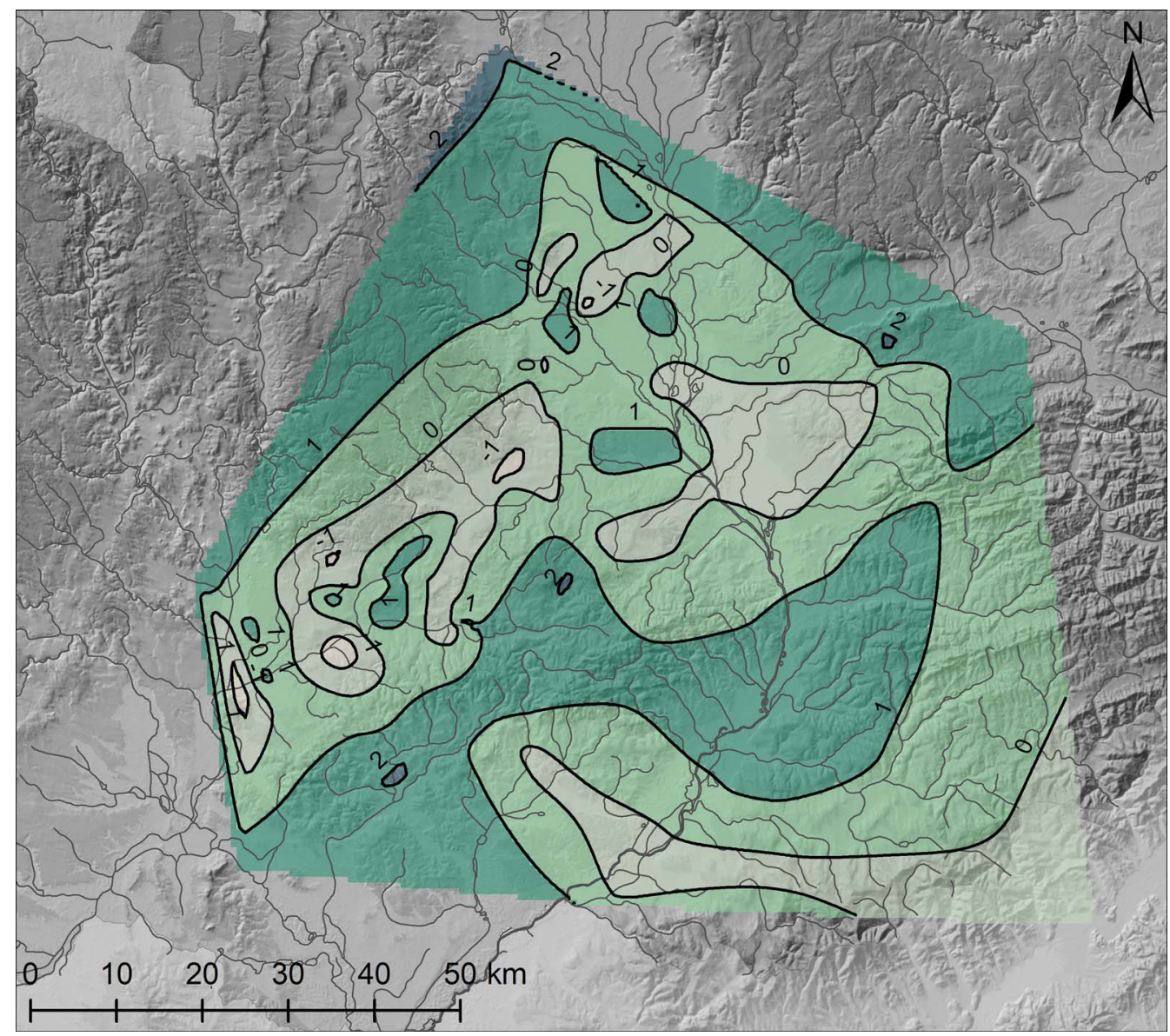

Figure 4. Correspondence analysis in geographical space; the factor score of burial sites on the first axis is illustrated in Figure 3 (only burial sites with more than two contexts; natural neighbour method of interpolation; figure by J. Kolarr, modified from Kolãr 2018: fig. 94).

\section{Full citation}

Kolář́, J. 2020. Migrations or local interactions? Spheres of interaction in third-millennium BC
Central Europe. Antiquity 94: 1168-85.

https://doi.org/10.15184/aqy.2020.151

(C) The Author(s), 2020. Published by Cambridge University Press on behalf of Antiquity Publications Ltd 